\title{
Incidence of and Factors Associated with New-Onset Insomnia Among Lebanese Hospitalised Patients
}

\author{
A single-centre study
}

Nour Sakr, ${ }^{1}$ "Souheil Hallit, ${ }^{1,2,4}$ Hanna Mattar ${ }^{1,3,4}$

ABSTRACT: Objectives: This study aimed to determine the incidence and post-discharge resolution of new-onset insomnia in hospitalised patients with no previous history of insomnia, as well as to define major correlates of in-hospital insomnia. Methods: This prospective observational study was conducted between November 2019 and January 2020 at a tertiary care centre in Lebanon. All hospitalised patients $>18$ years of age with no history of insomnia were screened for new-onset insomnia using the Insomnia Severity Index (ISI) scale. Subsequently, patients were re-assessed two weeks after discharge to determine insomnia resolution. Results: A total of 75 patients were included in the study. Of these, nine (12\%) had no insomnia, 34 (45.3\%) had subthreshold insomnia, 22 (29.3\%) had moderate insomnia and 10 (13.3\%) had severe insomnia. The mean ISI score was $14.95 \pm 6.05$, with $88 \%$ of patients having ISI scores of $>7$ ( $95 \%$ confidence interval: 0.822-0.965). The frequency of new-onset insomnia was significantly higher among patients who shared a room compared to those in single-bed rooms $(95.7 \%$ versus $75 \% ; P=0.011)$. Other factors were not found to be associated with new-onset insomnia, including the administration of medications known to cause insomnia, in-hospital sedative use, overnight oxygen, cardiac monitoring and self-reported nocturnal toilet use. Overall, insomnia resolution occurred in $78.7 \%$ of patients two weeks after discharge. Conclusion: There was a high incidence of acute new-onset insomnia among hospitalised patients at a tertiary centre in Lebanon. Additional research is recommended to further examine inhospital sleep disturbance factors and to seek convenient solutions to limit insomnia.

Keywords: Sleep Wake Disorders; Insomnia; Hospitalization; Incidence; Risk Factors; Lebanon.

\section{ADVANCES IN KNOWLEDGE}

This study provides important information regarding the incidence of new-onset insomnia among hospitalised patients, as well as associated factors and resolution rates. To the best of the authors' knowledge, only one previous study on this topic has been reported in the literature.

In particular, sharing a room was an extrinsic factor found to be associated with the development of new-onset insomnia among hospitalised patients.

Although the rate of in-hospital new-onset insomnia was high, the majority of cases resolved within two weeks of discharge, thus confirming that the onset of the insomnia was related to the hospitalisation.

\section{Application to Patient Care}

The findings of this study underline the importance of making environmental improvements to hospitals in order to enhance sleep quality among inpatients, for instance by separating patients into single-bed rooms. This would lead to fewer sleep disturbances during hospital stays, thereby potentially resulting in better outcomes in terms of patient satisfaction and wellbeing.

\section{$\mathrm{T}$} HE Suprachiasmatic hypothalamic nucleus of the brain is responsible for regulating circadian rhythm by synchronising the body's internal clock to the light-dark cycle, thus helping to determine sleep-wake patterns. ${ }^{1}$ However, environmental factors such as changes in season, temperature and feeding schedules, as well as deregulations to this biological clock, can disrupt sleep physiology by altering several circadian clock genes present in the suprachiasmatic nucleus, potentially resulting in sleep disorders. ${ }^{1}$ Insomnia is the most common of all sleep disorders and represents a significant public and mental health concern., ${ }^{2,3}$ However, defining and evaluating the prevalence of this disorder is challenging due to its heterogeneity in terms of duration, type and aetiology. ${ }^{3}$ As a result, the estimated prevalence of insomnia in the general population varies widely from $10-40 \% .4,5$

According to the Diagnostic and Statistical Manual of Mental Disorders, insomnia is defined as "dissatisfaction with sleep quantity or quality, with one or more of the following symptoms: difficulty in initiating sleep, maintaining sleep, and earlymorning awakening with inability to return to sleep"6,7 
Moreover, it may cause significant impairment in daytime functioning, as indicated by: "fatigue or low energy, daytime sleepiness, cognitive impairment, mood disturbance, behavioral difficulties, impaired occupational or social function, and negative effect on caregiver or family functioning", ${ }^{6,7}$ Insomnia is also categorised based on duration into acute/shortterm, intermittent or chronic types. Chronic insomnia occurs at least three nights per week for at least three months, despite adequate opportunity for sleep. ${ }^{8,9}$ Various risk factors for insomnia have been identified including gender, age, depression, regular use of sedative-hypnotic drugs, the onset of menses, previous insomnia complaints, snoring, low levels of physical activity, comorbidities and nocturnal micturition., ${ }^{4,9-13}$

Hospitalisation can often result in a period of acute sleep deprivation. ${ }^{10}$ Multiple factors have been found to interfere with inpatient sleep including patient-related factors such as pre-existing anxiety, schizophrenia and depression, illness-related factors such as pain, hyperarousal, whole-body metabolic rate and circadian deregulation and environmental factors such as noise and lighting. ${ }^{1,47-9,14-17}$ Several studies have confirmed that hospitalisation can have a major impact on sleep quality and quantity. For example, Talih et al. found that $67.4 \%$ of hospitalised psychiatric patients had insomnia.. ${ }^{9}$ Other studies conducted in hospital settings have reported rates of insomnia ranging from 50-73\%, with sleep complaints persisting for several months to 11 years post-discharge. ${ }^{11,18}$

However, to the best of the authors' knowledge, only one previous study has sought to assess the incidence of new-onset insomnia in patients admitted to general medical wards without a prior history of insomnia. ${ }^{8}$ As such, the current study aimed to determine the incidence of new-onset insomnia among hospitalised patients at a tertiary care centre in Lebanon with no history of insomnia, define the major correlates of in-hospital insomnia and report the rate of insomnia resolution after discharge.

\section{Methods}

This prospective observational study was conducted from November 2019 to January 2020 at the Notre Dame des Secours University Hospital (CHU-NDS) in Byblos, Lebanon. All Arabic-speaking patients aged $>18$ years old admitted to various medical and surgical wards at CHU-NDS during this period were included in the study. Only patients staying in the hospital for a minimum of two days were included in the study to ensure at least one night of in-hospital sleep. Patients with cognitive impairment, delirium, major hearing loss and infectious diseases were excluded, as were those who were immune-compromised, intubated or who used sleep-aid medications or sedatives.

An Arabic-language questionnaire was used to collect data from potential participants. The first section incorporated an Arabic version of the 7-item Insomnia Severity Index (ISI) scale to assess the severity of sleep-onset, sleep-maintenance and earlyawakening insomnias as well as satisfaction with current sleep patterns, interference with daytime functioning, noticeability of impairment to others and level of distress caused by the sleep problem. ${ }^{19,20}$ The ISI scale has been previously validated in Lebanon and measures insomnia severity on a 5-point Likert scale ranging from 0 (not at all severe) to 4 (very severe). ${ }^{19,20}$ Total scores range from $0-28$, with scores of $0-7,8-14,15-21$ and $22-28$ deemed indicative of no clinically significant insomnia, subthreshold insomnia, moderate insomnia and severe insomnia, respectively. ${ }^{19}$ The internal consistency of this section was acceptable (Cronbach's alpha: 0.88). Subsequently, at follow-up, patients with new-onset insomnia were contacted by telephone two weeks after discharge, with ISI scores of $<7$ deemed indicative of insomnia resolution.

The second section of the questionnaire comprised an Arabic version of the validated 19-item Pittsburgh Sleep Quality Index (PSQI) scale. ${ }^{21,22}$ Items in this scale are combined to form seven component subscales assessing subjective sleep quality, sleep latency, sleep duration, habitual sleep efficiency, sleep disturbances, use of sleep medications and daytime dysfunction. ${ }^{21}$ Each subscale is scored from 0 to 3, with total scores ranging from $0-21$. Higher scores are indicative of poorer sleep quality, with a cut-off value of $\geq 5$ distinguishing poor sleepers. ${ }^{21}$ This was used to exclude patients with a positive history of insomnia prior to admission. Arabic versions of both the ISI and PSQI scales were used for the purposes of the current study, since Arabic is the native language in Lebanon. These translated versions have been validated in previous studies..$^{22,23}$

Finally, the third part of the questionnaire collected information regarding selected variables in order to compare associations with the distribution of insomnia. This information included the participants' gender, age, basic sociodemographic characteristics, education level, assigned ward, drugs taken during admission, use of overnight oxygen, cardiac monitoring, type of hospital room (i.e. single-bed or shared), hospitalisation date and overall hospital stay duration. Factors deemed to affect sleep included interruptions by nurses to draw blood or check vital signs, noise 


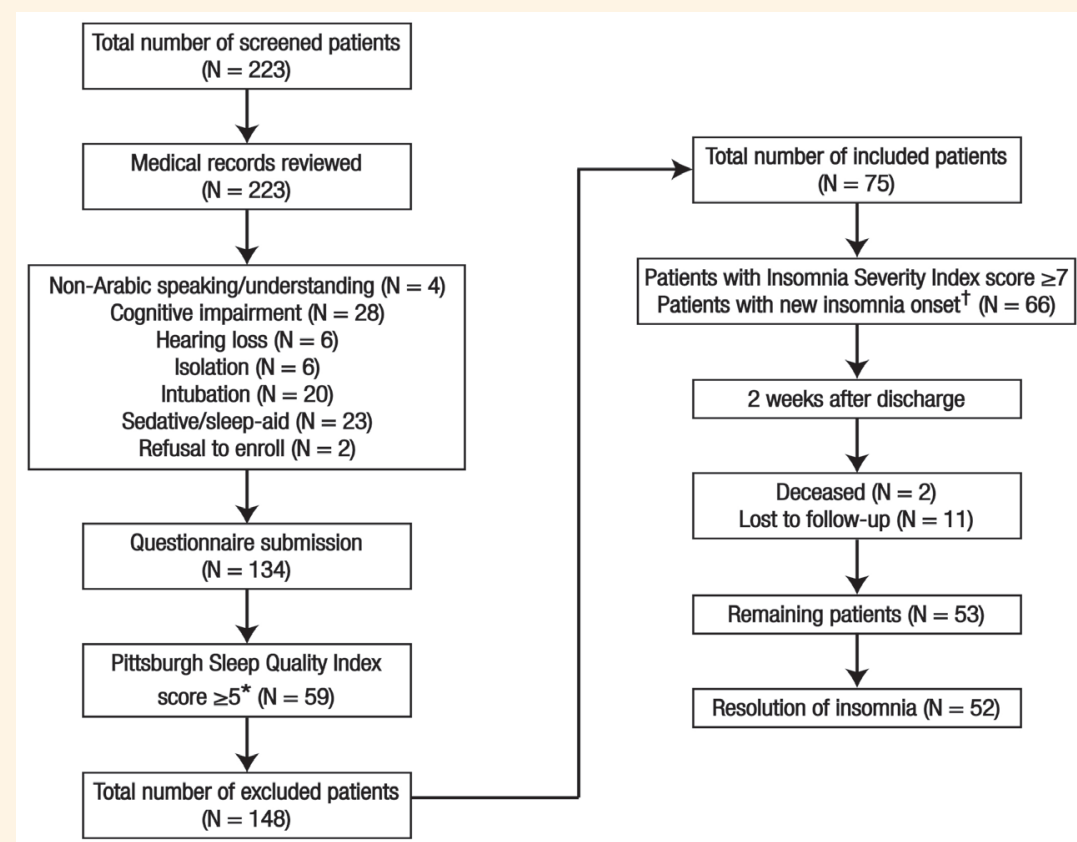

Figure 1: Diagram showing the inclusion of patients in the current study.

"Assessed using an Arabic version of the 19-item Pittsburgh Sleep Quality Index scale. ${ }^{22.23}$ Scores of $\geq 5$ were considered indicative of a past history of insomnia. ${ }^{22}{ }^{+}$Assessed using an Arabic version of the 7-item Insomnia Severity Index. ${ }^{19,20}$ Scores of $>7$ were considered indicative of new-onset insomnia. ${ }^{19}$

and lighting, lack of familiarity with the hospital environment, pain and other disease symptoms and anxiety and stress.

Data were retrieved from the patients' medical records to determine eligibility for participation in the study. In order to provide adequate power for bivariate and multivariate analyses, the necessary sample size was calculated to be 72 using Epi Info ${ }^{\mathrm{TM}}$ software tools (Centers for Disease Control and Prevention, Atlanta, Georgia, USA), based on a total number of hospital beds of 90, a frequency of insomnia incidence of $36 \%$ and at a $95 \%$ confidence interval. ${ }^{8}$ Initially, a total of 223 medical records were reviewed, after which 89 patients were excluded due to not meeting the inclusion criteria. The remaining 134 patients completed the questionnaire during 10-minute bedside face-to-face interviews with a single researcher in order to decrease interrater variability and prevent any confusion, omission or misunderstanding regarding the questions. Thereafter, 59 patients with PSQI scores of $\geq 5$ were excluded due to a past history of insomnia in the month prior to their hospitalisation. ${ }^{21}$ As such, 75 patients with PSQI scores of $<5$ were included in the final analysis [Figure 1]. No significant differences were observed between eligible patients with and without a prior history of insomnia, except for body mass index (BMI) [Table 1].

Data were analysed using the Statistical Package for the Social Sciences (SPSS), Version 25.0 (IBM Corp., Armonk, New York, USA). Since the sample was not normally distributed, non-parametric tests were used. McNemar's test was used to compare categorical variables, while a Mann-Whitney U test was used to compare two means. A Wilcoxon signedrank test was used to compare mean ISI scores during hospitalisation and post-discharge. Multinomial logistic regression analysis was conducted, using categories of insomnia as the dependent variable with the absence of insomnia as the reference category. Subsequently, all significant variables were included in the bivariate analysis as independent variables. A repeated-measures analysis of variance (ANOVA) was conducted to determine factors influencing the resolution of insomnia after discharge, after adjusting for sociodemographic variables. A $P$ value of $<0.050$ was considered statistically significant.

Ethical approval for this study was obtained from the institutional ethics committee of CHU-NDS. Written informed consent was obtained from each patient prior to participation in the study.

\section{Results}

Of the 75 patients included in the final analysis, nine (12\%) had no insomnia, 34 (45.3\%) had subthreshold insomnia, 22 (29.3\%) had moderate insomnia and 10 (13.3\%) had severe insomnia. The mean ISI score was $14.95 \pm 6.05$. In total, 66 patients had ISI scores of $>7$ (95\% confidence interval [CI]: 0.822-0.965), resulting in an overall rate of new-onset insomnia of $88 \%$. 
Table 1: Differences between hospitalised patients with and without a prior history of insomnia at a tertiary care centre in Lebanon $(\mathrm{N}=134)$

\begin{tabular}{|c|c|c|c|}
\hline \multirow[t]{2}{*}{ Variable } & \multicolumn{2}{|c|}{ Hospitalised patients, n (\%) } & \multirow[t]{2}{*}{$P$ value } \\
\hline & $\begin{array}{l}\text { Without a } \\
\text { prior history } \\
\text { of insomnia } \\
(\mathbf{n}=75)\end{array}$ & $\begin{array}{l}\text { With a prior } \\
\text { history of } \\
\text { insomnia* } \\
(\mathbf{n}=59)\end{array}$ & \\
\hline $\begin{array}{l}\text { Mean age in } \\
\text { years } \pm S D\end{array}$ & $52.37 \pm 18.41$ & $55.12 \pm 16.27$ & 0.554 \\
\hline $\begin{array}{l}\text { Mean BMI in } \\
\mathrm{kg} / \mathrm{m}^{2} \pm \mathrm{SD}\end{array}$ & $28.15 \pm 4.92$ & $25.85 \pm 4.28$ & $0.006^{\dagger}$ \\
\hline \multicolumn{4}{|c|}{ Mean hospital stay \pm SD } \\
\hline $\begin{array}{l}\text { Assumed } \\
\text { hospital stay } \\
\text { in days }\end{array}$ & $6.16 \pm 3.51$ & $6.68 \pm 4.53$ & 0.893 \\
\hline $\begin{array}{l}\text { Actual } \\
\text { hospital stay } \\
\text { in days }\end{array}$ & $4.07 \pm 2.99$ & $4.49 \pm 3.46$ & 0.674 \\
\hline Gender & & & 0.775 \\
\hline Male & $35(54.7)$ & $29(45.3)$ & \\
\hline Female & $40(57.1)$ & $30(42.9)$ & \\
\hline \multicolumn{3}{|c|}{ Type of insurance } & 0.340 \\
\hline No coverage & $4(80)$ & $1(20)$ & \\
\hline COOP & $3(33.3)$ & $6(66.7)$ & \\
\hline Army & $14(56)$ & $11(44)$ & \\
\hline $\mathrm{MOPH}$ & $5(50)$ & $5(50)$ & \\
\hline NSSF & $23(50)$ & $23(50)$ & \\
\hline Private & $26(66.7)$ & $13(33.3)$ & \\
\hline \multicolumn{3}{|c|}{ Monthly salary in USD } & 0.289 \\
\hline None & $29(58)$ & $21(42)$ & \\
\hline$<1,000$ & $22(66.7)$ & $11(33.3)$ & \\
\hline $1,000-2,000$ & $22(45.8)$ & $26(54.2)$ & \\
\hline$>2,000$ & $2(66.7)$ & $1(33.3)$ & \\
\hline \multicolumn{3}{|l|}{ Education level } & 0.447 \\
\hline $\begin{array}{l}\text { Illiterate/ } \\
\text { primary } \\
\text { school }\end{array}$ & $5(38.5)$ & $8(61.5)$ & \\
\hline Elementary & $7(46.7)$ & $8(53.3)$ & \\
\hline Secondary & $19(59.4)$ & $13(40.6)$ & \\
\hline University & $44(59.5)$ & $30(40.5)$ & \\
\hline \multicolumn{3}{|l|}{ Hospital ward } & 0.276 \\
\hline Surgery & $11(45.8)$ & $13(54.2)$ & \\
\hline Cardiology & 7 (38.9) & $11(61.1)$ & \\
\hline $\begin{array}{l}\text { Internal } \\
\text { medicine }\end{array}$ & $20(57.1)$ & $15(42.9)$ & \\
\hline First-class & 17 (77.3) & $5(22.7)$ & \\
\hline ICU & $2(50)$ & $2(50)$ & \\
\hline
\end{tabular}

$\begin{array}{lcc}\begin{array}{l}\text { Gynaecology/ } \\ \text { obstetrics }\end{array} & 15(60) & 10(40) \\ \begin{array}{l}\text { Haematology/ } \\ \text { oncology }\end{array} & 3(50) & 3(50) \\ \begin{array}{l}\text { Type of hospital room } \\ \text { Single-bed }\end{array} & 28(68.3) & 13(31.7) \\ \text { Shared } & 47(50.5) & 46(49.5)\end{array}$

0.056

$S D=$ standard deviation; $B M I=$ body mass index COOP = Cooperative insurance; $M O P H=$ Ministry of Public Health; NSSF = National Social Security Fund; USD = United States dollars; ICU = intensive care unit. *Assessed using an Arabic version of the 19-item Pittsburgh Sleep Quality Index scale. ${ }^{22,23}$ Scores of $\geq 5$ were considered indicative of a past history of insomnia. ${ }^{22}{ }^{\dagger}$ Statistically significant at $P<0.050$.

Table 2: Bivariate analysis of factors associated with newonset insomnia among hospitalised patients without a prior history of insomnia at a tertiary care centre in Lebanon $(\mathrm{N}=75)$

\begin{tabular}{|c|c|c|c|}
\hline \multirow[t]{2}{*}{ Variable } & \multicolumn{2}{|c|}{ Hospitalised patients, $\mathbf{n}(\%)$} & $P$ \\
\hline & $\begin{array}{l}\text { Without } \\
\text { new-onset } \\
\text { insomnia } \\
(\mathbf{n}=9)\end{array}$ & $\begin{array}{c}\text { With } \\
\text { new-onset } \\
\text { insomnia* } \\
(n=66)\end{array}$ & \\
\hline $\begin{array}{l}\text { Mean age in } \\
\text { years } \pm \text { SD }\end{array}$ & $51.00 \pm 17.03$ & $52.56 \pm 18.70$ & 0.769 \\
\hline $\begin{array}{l}\text { Mean BMI in } \\
\mathrm{kg} / \mathrm{m}^{2} \pm \mathrm{SD}\end{array}$ & $27.45 \pm 5.45$ & $28.25 \pm 4.88$ & 0.068 \\
\hline
\end{tabular}

Mean hospital stay \pm SD

$\begin{array}{lccc}\begin{array}{l}\text { Assumed } \\ \text { hospital stay } \\ \text { in days }\end{array} & 6.00 \pm 7.26 & 5.94 \pm 2.91 & 0.234 \\ \begin{array}{l}\text { Actual } \\ \text { hospital stay } \\ \text { in days }\end{array} & 4.44 \pm 5.57 & 3.99 \pm 2.50 & 0.514 \\ \begin{array}{l}\text { Mean number } \\ \text { of awakenings } \\ \text { per night } \pm \text { SD }\end{array} & 0.78 \pm 1.09 & 3.85 \pm 2.80 & <0.001^{\dagger} \\ \begin{array}{l}\text { Gender } \\ \text { Male }\end{array} & 3(10.7) & 25(89.3) & \\ \text { Female } & 6(12.8) & 41(87.2) & \\ \text { Insurance } & & & \\ \text { No } & 1(25) & 3(75) & \\ \text { Yes } & 8(11.3) & 63(88.7) & \end{array}$

Monthly salary in USD

$\begin{array}{lcc}\text { None } & 5(20.8) & 19(79.2) \\ <1,000 & 1(4.5) & 21(95.5) \\ 1,000-2,000 & 3(11.5) & 23(88.5) \\ >2,000 & 0(0) & 3(100)\end{array}$

$S D=$ standard deviation $; B M I=$ body mass index $; U S D=$ United States dollars; ICU = intensive care unit. "Assessed using an Arabic version of the 7-item Insomnia Severity Index. ${ }^{19,20}$ Scores of $>7$ were considered indicative of new-onset insomnia. ${ }^{19}{ }^{+}$Statistically significant at $P<0.050$. 
Table 2 (cont'd): Bivariate analysis of factors associated with new-onset insomnia among hospitalised patients without a prior history of insomnia at a tertiary care centre in Lebanon $(\mathrm{N}=75)$

\begin{tabular}{|c|c|c|c|}
\hline \multirow[t]{2}{*}{ Variable } & \multicolumn{2}{|c|}{ Hospitalised patients, n (\%) } & \multirow{2}{*}{$\begin{array}{c}P \\
\text { value }\end{array}$} \\
\hline & $\begin{array}{c}\text { Without } \\
\text { new-onset } \\
\text { insomnia } \\
(\mathbf{n}=9)\end{array}$ & $\begin{array}{c}\text { With } \\
\text { new-onset } \\
\text { insomnia* } \\
(n=66)\end{array}$ & \\
\hline \multicolumn{3}{|l|}{ Education level } & 0.259 \\
\hline $\begin{array}{l}\text { Illiterate/ } \\
\text { primary }\end{array}$ & $2(40)$ & $3(60)$ & \\
\hline Elementary & $0(0)$ & $7(100)$ & \\
\hline Secondary & $2(10.5)$ & $17(89.5)$ & \\
\hline University & 5 (11.4) & $39(88.6)$ & \\
\hline \multicolumn{3}{|l|}{ Hospital ward } & 0.167 \\
\hline Surgery & $0(0)$ & $12(100)$ & \\
\hline Cardiology & $3(33.3)$ & $6(66.7)$ & \\
\hline $\begin{array}{l}\text { Internal } \\
\text { medicine }\end{array}$ & $2(13.3)$ & $13(86.7)$ & \\
\hline First-class & $3(25)$ & $9(75)$ & \\
\hline $\mathrm{ICU}$ & $0(0)$ & $2(100)$ & \\
\hline $\begin{array}{l}\text { Gynaecology/ } \\
\text { obstetrics }\end{array}$ & $1(5.3)$ & $18(94.7)$ & \\
\hline $\begin{array}{l}\text { Haematology/ } \\
\text { oncology }\end{array}$ & $0(0)$ & $6(100)$ & \\
\hline \multicolumn{3}{|c|}{ Type of hospital room } & $0.011^{+}$ \\
\hline Single-bed & $7(25.0)$ & $21(75.0)$ & \\
\hline Shared & $2(4.3)$ & $45(95.7)$ & \\
\hline \multicolumn{3}{|c|}{ Self-reported nocturnal toilet use } & 0.407 \\
\hline No & $8(11.3)$ & $63(88.7)$ & \\
\hline Yes & $1(25)$ & $3(75)$ & \\
\hline \multicolumn{3}{|l|}{ Night oxygen use } & $>0.999$ \\
\hline No & $8(12.1)$ & $58(87.9)$ & \\
\hline Yes & $1(11.1)$ & $8(88.9)$ & \\
\hline \multicolumn{3}{|c|}{ Cardiac monitoring } & $>0.999$ \\
\hline No & $9(12.3)$ & $64(87.7)$ & \\
\hline Yes & $0(0)$ & $2(100)$ & \\
\hline \multicolumn{3}{|c|}{ In-hospital sedative use } & $>0.999$ \\
\hline No & $9(12.7)$ & $62(87.3)$ & \\
\hline Yes & $0(0)$ & $4 \cdot(100)$ & \\
\hline
\end{tabular}

$S D=$ standard deviation; $B M I=$ body mass index; $U S D=$ United States dollars; ICU = intensive care unit. "Assessed using an Arabic version of the 7-item Insomnia Severity Index..$^{19,20}$ Scores of $>7$ were considered indicative of new-onset insomnia. ${ }^{19}{ }^{+}$Statistically significant at $P<0.050$.
Table 3: Bivariate analysis of factors perceived to influence new-onset insomnia among hospitalised patients without a prior history of insomnia at a tertiary care centre in Lebanon $(\mathrm{N}=75)$

$\begin{array}{lcc}\text { Perceived } & \text { Hospitalised patients, n (\%) } & \text { P value } \\ \text { impact } & \text { Without } & \text { With } \\ & \begin{array}{c}\text { new-onset } \\ \text { insomnia } \\ (\mathrm{n}=9)\end{array} & \begin{array}{c}\text { new-onset } \\ \text { insomnia* } \\ (\mathrm{n}=66)\end{array}\end{array}$

Environmental changes

0.060

$\begin{array}{lcc}\text { None/little } & 8(21.1) & 30(78.9) \\ \begin{array}{l}\text { Mild/ } \\ \text { moderate }\end{array} & 1(4.8) & 20(95.2) \\ \begin{array}{l}\text { Severe/very } \\ \text { severe }\end{array} & 0(0) & 16(100)\end{array}$

severe

Nurse-related factors

0.104

$\begin{array}{lcc}\text { None/little } & 7(17.9) & 32(82.1) \\ \begin{array}{l}\text { Mild/ } \\ \text { moderate }\end{array} & 2(13.3) & 13(86.7) \\ \begin{array}{l}\text { Severe/very } \\ \text { severe }\end{array} & 0(0) & 21(100) \\ \begin{array}{l}\text { Disease and pain } \\ \text { None/little }\end{array} & 7(18.4) & 31(81.6) \\ \begin{array}{l}\text { Mild/ } \\ \text { moderate }\end{array} & 2(11.1) & 16(88.9) \\ \begin{array}{l}\text { Severe/very } \\ \text { severe }\end{array} & 0(0) & 19(100)\end{array}$

Severe/very $\quad 0(0)-19(100)$

severe

Respiratory symptoms

None/little $\quad 9(14.1) \quad 55(85.9)$

Mild/ $\quad 0(0) \quad 2(100)$

moderate

Severe/very $\quad 0(0) \quad 9(100)$

severe

Noise and light disturbances

0.636

8 (15.4)

$44(84.6)$

$0(0)$

9 (100)

moderate

$1(7.1)$

$13(92.9)$

Severe/very

0.119

severe

Stress and anxiety

None/little $\quad 7(14.9) \quad 40(85.1)$

Mild/ $\quad 2(16.7) \quad 10(83.3)$

moderate

Severe/very $\quad 0(0) \quad 16(100)$

severe

Sharing a room

None/little $\quad 9(16.1) \quad 47(83.9)$

Mild/ $\quad 0(0) \quad 10(100)$

moderate

$0(0) \quad 9(100)$

Severe/very

severe

*Assessed using an Arabic version of the 7-item Insomnia Severity Index. ${ }^{19,20}$ Scores of $>7$ were considered indicative of new-onset insomnia. ${ }^{19}$ 
Table 4: Bivariate analysis of medications associated with new-onset insomnia among hospitalised patients without a prior history of insomnia at a tertiary care centre in Lebanon $(\mathrm{N}=75)$

\begin{tabular}{|c|c|c|c|}
\hline \multirow{2}{*}{$\begin{array}{l}\text { Medication } \\
\text { taken }\end{array}$} & \multicolumn{2}{|c|}{ Hospitalised patients, n (\%) } & \multirow{2}{*}{$\begin{array}{c}P \\
\text { value }\end{array}$} \\
\hline & $\begin{array}{l}\text { Without new- } \\
\text { onset insomnia } \\
\quad(\mathbf{n}=9)\end{array}$ & $\begin{array}{l}\text { With new-onset } \\
\text { insomnia** } \\
(\mathrm{n}=66)\end{array}$ & \\
\hline \multicolumn{3}{|c|}{ Corticosteroids } & 1 \\
\hline No & $8(12.9)$ & $54(87.1)$ & \\
\hline Yes & $1(7.7)$ & $12(92.3)$ & \\
\hline \multicolumn{3}{|l|}{ Levothyroxine } & 1 \\
\hline No & $9(12.5)$ & $63(87.5)$ & \\
\hline Yes & $0(0)$ & $3(100.0)$ & \\
\hline \multicolumn{3}{|c|}{ Proton pump inhibitors } & 0.720 \\
\hline No & $5(10.6)$ & $42(89.4)$ & \\
\hline Yes & $4(14.3)$ & 24. (85.7) & \\
\hline \multicolumn{3}{|c|}{ Anti-viral medications } & 1 \\
\hline No & $9(12.9)$ & $61(87.1)$ & \\
\hline Yes & $0(0)$ & $5(100.0)$ & \\
\hline \multicolumn{3}{|l|}{ Carbapenems } & 0.549 \\
\hline No & $8(11.6)$ & $61(88.4)$ & \\
\hline Yes & $1(16.7)$ & $5(83.3)$ & \\
\hline \multicolumn{3}{|c|}{ Cephalosporins } & 0.674 \\
\hline No & $8(13.8)$ & $50(86.2)$ & \\
\hline Yes & $1(5.9)$ & $16(94.1)$ & \\
\hline \multicolumn{3}{|l|}{ Paracetamol } & 1 \\
\hline No & $8(13.1)$ & $53(86.9)$ & \\
\hline Yes & $1(7.1)$ & $13(92.9)$ & \\
\hline \multicolumn{3}{|c|}{ Non-steroidal anti-inflammatory drugs } & 0.588 \\
\hline No & $9(13.6)$ & $57(86.4)$ & \\
\hline Yes & $0(0)$ & $9(100.0)$ & \\
\hline \multicolumn{3}{|l|}{$\begin{array}{l}\text { Beta- } \\
\text { blockers }\end{array}$} & 0.344 \\
\hline No & $7(10.8)$ & $58(89.2)$ & \\
\hline Yes & $2(20.0)$ & $8(80.0)$ & \\
\hline \multicolumn{3}{|l|}{ Diuretics } & 0.294 \\
\hline No & $7(10.6)$ & $59(89.4)$ & \\
\hline Yes & $2(22.2)$ & $7(77.8)$ & \\
\hline \multicolumn{3}{|l|}{ Pregabalin } & 1 \\
\hline No & $9(12.7)$ & $62(87.3)$ & \\
\hline Yes & $0(0)$ & $4(100.0)$ & \\
\hline \multicolumn{3}{|c|}{ Anti-spasmodic drugs } & 1 \\
\hline No & $9(12.5)$ & $63(87.5)$ & \\
\hline
\end{tabular}

$\begin{array}{lccc}\text { Yes } & 0(0) & 3(100.0) & \\ \text { Statins } & & & 1 \\ \text { No } & 9(12.5) & 63(87.5) & \\ \text { Yes } & 0(0) & 3(100.0) & \\ \text { Anti-emetic drugs } & & & \\ \text { No } & 9(12.7) & 62(87.3) & \\ \text { Yes } & 0(0) & 4(100.0) & \\ \text { Quinolones } & & & \\ \text { No } & 8(11.0) & 65(89.0) & \\ \text { Yes } & 1(50.0) & 1(50.0) & \\ \text { Bronchodilators } & & & \\ \text { No } & 9(12.9) & 61(87.1) & \\ \text { Yes } & 0(0) & 5(100.0) & \\ \text { Allopurinol } & & 64(87.7) & \\ \text { No } & 9(12.3) & 2(100.0) & \\ \text { Yes } & 0(0) & 1 \\ \text { Nes } & & \end{array}$

*Assessed using an Arabic version of the 7-item Insomnia Severity Index. ${ }^{19,20}$ Scores of $>7$ were considered indicative of new-onset insomnia. ${ }^{19}$

Among patients in this category, the average score for each component in the ISI scale was as follows: 2.76 for difficulty falling asleep, 3.13 for maintaining asleep, 2.69 for waking up too early, 2.55 for sleep satisfaction, 1.68 for noticeability of impairment to others, 1.44 for being worried about insomnia and 1.88 for interference with daytime functioning.

The bivariate analysis showed that a significantly higher percentage of patients in shared rooms developed new-onset insomnia compared to those admitted to single-bed rooms (95.7\% versus $75 \% ; P=0.011$ ). In addition, patients with new-onset insomnia had a higher mean number of awakenings during the night compared to those who did not $(3.85 \pm 2.80$ versus $0.78 \pm 1.09$ awakenings; $P<0.001$ ). However, no significant differences were noted with regards to any of the other variables assessed [Tables 2 and 3], including the administration of medications known to cause insomnia [Table 4].

Patients with subthreshold insomnia were significantly older (mean age: $57.85 \pm 18.75$ years; $P=0.041$ ) and had longer hospital stays (mean stay duration: 4.41 \pm 2.74 days; $P=0.050$ ) compared to those with other categories of insomnia. In addition, a significantly higher percentage of individuals in this category had insurance (47.9\% versus $11.3-29.6 \% ; P=0.039$ ). Moreover, patients with subthreshold insomnia more frequently perceived environmental changes (52.4\% versus $4.8-28.6 \% ; P=0.045)$, nurse-related factors (46.7\% versus $0-40 \% ; P=0.003)$ and stress and anxiety 
(50\% versus $16.7 \% ; P=0.003$ ) to have only a mild/ moderate effect on their insomnia, whereas patients with moderate insomnia more frequently perceived noise and light disturbances to have a mild/moderate effect (66.7\% versus $0-33.3 \%$; $P=0.001)$. Finally, patients with severe insomnia more frequently awoke during the night (mean number of awakenings: $5.30 \pm 2.06$; $P<0.001$ ) [Tables 5 and 6].

Of the 66 patients diagnosed with new-onset inhospital insomnia, follow-up ISI scores two weeks after discharge indicated insomnia resolution in 52 (78.7\%). There was a significant decrease in mean ISI scores post-discharge ( 2.08 versus $14.95 \pm 6.05 ; \mathrm{t}=15.57$; degrees of freedom $=48 ; P<0.001)$. According to the repeated-measures ANOVA, no factors were associated with the decrease in mean ISI score. A multinomial logistic regression analysis indicated that number of awakenings per night was significantly associated with the likelihood of subthreshold insomnia (adjusted odds ratio $[\mathrm{aOR}]=2.30,95 \% \mathrm{CI}: 1.35-3.93 ; P=0.002)$, moderate insomnia (aOR $=2.76,95 \% \mathrm{CI}: 1.60-4.75$; $P<0.001)$ and severe insomnia $(\mathrm{aOR}=2.90,95 \%$ CI: 1.67-5.03; $P<0.001)$. No other variables entered into the model were significant including age, BMI, assumed duration of hospital stay and the perceived impact of environmental changes, noise and light disturbances, nurse-related factors and stress and anxiety.

\section{Discussion}

This prospective observational study aimed to document the incidence, resolution and factors associated with the development of new-onset insomnia in hospitalised patients at a tertiary care centre in Lebanon. To the best of the authors' knowledge, this is only the second study worldwide to assess the development of newonset insomnia among inpatients with no prior history of insomnia. ${ }^{8}$ Overall, the rate of new-onset insomnia in the current study was $88 \%$, with $45.3 \%$ of patients having subthreshold insomnia and $42.7 \%$ having clinically significant moderate or severe insomnia. However, in a comparable study, Ho et al. reported a much lower overall incidence rate of $36 \%$, with $26 \%$ of patients having subthreshold insomnia and only $10 \%$ suffering from moderate or severe insomnia. ${ }^{8}$

Various factors could be responsible for this difference in findings. For instance, the present study included patients admitted to various medical and surgical wards, including the internal medicine, cardiology, haematology/oncology, first-class and gynaecology/obstetrics wards as well as the intensive care unit (ICU). In contrast, Ho et al. included only patients admitted to medical wards. ${ }^{8}$ However, all
12 patients (100\%) admitted to the surgical ward in the current study developed new-onset insomnia, representing the highest rate of all wards and hospital areas outside of the ICU. It is therefore possible that the inclusion of such patients contributed to an increase in the incidence of new-onset insomnia in the current study in comparison to previous research. ${ }^{8}$ Moreover, it is important to mention that the rate of new-onset insomnia reported by Ho et al. is low in comparison to findings from other studies (38-57\%). ${ }^{8,10,11,13}$ Finally, the present study utilised a validated translated version of the PSQI in order to exclude patients with a prior history of insomnia, in contrast to the previous study which did not make use of a validated index to exclude patients. ${ }^{8,22}$ Lack of use of a PSQI cut-off score could have resulted in fewer excluded patients, thus opening the sample selection to bias.

Sharing a room was found to result in significantly greater odds of developing new-onset insomnia compared to those in single-bed hospital rooms. In comparison, this variable did not appear to be statistically significant in the previous study by Ho et al. ${ }^{8}$ The most probable explanation for this finding is that most patients at CHU-NDS are usually accompanied by a family member or other caregiver who also occupies the same room, thus making shared rooms even more crowded with an average of four people in a normally dual room. This would likely cause more frequent sleep disturbances to those in shared rooms. Similarly, the present study found that patients with new-onset insomnia had a significantly higher mean number of awakenings during the night (0.78 versus 3.85 awakenings; $P<0.001$ ), a finding in agreement with previous research $(0.9$ versus 1.35 awakenings; $P=0.027) .{ }^{8}$ As would be expected, this factor also significantly influenced insomnia category, with patients with severe insomnia more frequently waking at night (5.30 versus $0.78-4.36$ awakenings; $P$ $<0.001$ )

No significant differences were noticed between patients with and without new-onset insomnia in terms of sociodemographic parameters such as gender and age. These findings are comparable to those reported by Ho et al., apart from a slight difference in mean age in which patients with insomnia appeared to be younger (61 versus 63 years; $P=0.038$ ) ${ }^{8}$ In contrast, other researchers have shown that older adults suffer from increased sleep disturbances, particularly as they are usually more easily roused by increased noise or light, stimuli which commonly occur in a hospital environment. ${ }^{10}$ In the current study, other factors-such as the administration of medications known to cause insomnia, sedative use, overnight oxygen use, cardiac monitoring, self-reported nocturnal toilet use and 
Table 5: Bivariate analysis of factors associated with insomnia categories among hospitalised patients without a prior history of insomnia at a tertiary care centre in Lebanon $(\mathrm{N}=75)$

\begin{tabular}{|c|c|c|c|c|c|}
\hline \multirow[t]{2}{*}{ Variable } & \multicolumn{4}{|c|}{$\begin{array}{c}\text { Category of insomnia* } \\
\text { n (\%) }\end{array}$} & \multirow[t]{2}{*}{$P$ value } \\
\hline & $\begin{array}{l}\text { None } \\
(\mathrm{n}=9)\end{array}$ & $\begin{array}{l}\text { Subthreshold } \\
\qquad(\mathrm{n}=34)\end{array}$ & $\begin{array}{l}\text { Moderate } \\
(\mathrm{n}=22)\end{array}$ & $\begin{array}{l}\text { Severe } \\
(\mathbf{n}=10)\end{array}$ & \\
\hline Mean age in years \pm SD & $51.00 \pm 17.03$ & $57.85 \pm 18.75$ & $43.41 \pm 17.80$ & $54.70 \pm 13.51$ & $0.041^{\dagger}$ \\
\hline Mean BMI in $\mathrm{kg} / \mathrm{m}^{2} \pm \mathrm{SD}$ & $27.45 \pm 5.45$ & $27.34 \pm 4.48$ & $30.58 \pm 4.98$ & $26.21 \pm 4.42$ & 0.106 \\
\hline \multicolumn{6}{|l|}{ Mean hospital stay \pm SD } \\
\hline Assumed hospital stay in days & $6.00 \pm 7.26$ & $6.47 \pm 2.95$ & $5.27 \pm 2.51$ & $5.60 \pm 3.47$ & 0.093 \\
\hline Actual hospital stay in days & $4.44 \pm 5.57$ & $4.41 \pm 2.74$ & $3.13 \pm 1.72$ & $4.40 \pm 2.80$ & $0.050^{+}$ \\
\hline $\begin{array}{l}\text { Mean number of awakenings } \\
\text { per night }\end{array}$ & $0.78 \pm 1.09$ & $3.09 \pm 1.56$ & $4.36 \pm 4.05$ & $5.30 \pm 2.06$ & $<0.001^{+}$ \\
\hline Gender & & & & & 0.468 \\
\hline Male & $3(10.7)$ & $11(39.3)$ & $8(28.6)$ & $6(21.4)$ & \\
\hline Female & $6(12.8)$ & $23(48.9)$ & $14(29.8)$ & $4(8.5)$ & \\
\hline Insurance & & & & & $0.039^{+}$ \\
\hline No & $1(25)$ & $0(0)$ & $1(25)$ & $2(50)$ & \\
\hline Yes & $8(11.3)$ & $34(47.9)$ & $21(29.6)$ & $8(11.3)$ & \\
\hline Monthly salary in USD & & & & & 0.277 \\
\hline None & $5(20.8)$ & $12(50)$ & $5(20.8)$ & $2(8.3)$ & \\
\hline$<1,000$ & $1(4.5)$ & $13(59.1)$ & $6(27.3)$ & $2(9.1)$ & \\
\hline $1,000-2,000$ & $3(11.5)$ & $9(34.6)$ & $8(30.8)$ & $6(23.1)$ & \\
\hline$>2,000$ & $0(0)$ & $0(0)$ & $3(100)$ & $0(0)$ & \\
\hline Education level & & & & & 0.566 \\
\hline Illiterate/primary & $2(40)$ & $2(40)$ & $1(20)$ & $0(0)$ & \\
\hline Elementary & $0(0)$ & $4(57.1)$ & $1(14.3)$ & $2(28.6)$ & \\
\hline Secondary & $2(10.5)$ & $10(52.6)$ & $4(21.1)$ & $3(15.8)$ & \\
\hline University & $5(11.4)$ & $18(40.9)$ & $16(36.4)$ & $5(11.4)$ & \\
\hline Hospital ward & & & & & 0.419 \\
\hline Surgery & $0(0)$ & $4(33.3)$ & $6(50)$ & $2(16.7)$ & \\
\hline Cardiology & $3(33.3)$ & $5(55.6)$ & $1(11.1)$ & $0(0)$ & \\
\hline Internal medicine & $2(13.3)$ & $6(40)$ & $4(26.7)$ & $3(20)$ & \\
\hline First-class & $3(25)$ & $7(58.3)$ & $2(16.7)$ & $0(0)$ & \\
\hline $\mathrm{ICU}$ & $0(0)$ & $1(50)$ & $1(50)$ & $0(0)$ & \\
\hline Gynaecology/obstetrics & $1(5.3)$ & $9(47.4)$ & $5(26.3)$ & 4. (21.1) & \\
\hline Haematology/oncology & $0(0)$ & $2(33.3)$ & $3(50)$ & $1(16.7)$ & \\
\hline Type of hospital room & & & & & 0.505 \\
\hline Single-bed & $3(9.7)$ & $12(38.7)$ & $10(32.3)$ & $6(19.3)$ & \\
\hline Shared & $6(13.6)$ & $22(50.0)$ & $12(27.3)$ & $4(9.1)$ & \\
\hline Self-reported nocturnal toilet use & & & & & 0.365 \\
\hline No & $8(11.3)$ & $31(43.7)$ & $22(31)$ & $10(14.1)$ & \\
\hline Yes & $1(25)$ & $3(75)$ & $0(0)$ & $0(0)$ & \\
\hline Night oxygen use & & & & & 0.903 \\
\hline No & $8(12.1)$ & $30(45.5)$ & $20(30.3)$ & $8(12.1)$ & \\
\hline Yes & $1(11.1)$ & $4(44.4)$ & $2(22.2)$ & $2(22.2)$ & \\
\hline Cardiac monitoring & & & & & 0.528 \\
\hline No & $9(12.3)$ & $33(45.2)$ & $22(30.1)$ & $9(12.3)$ & \\
\hline Yes & $0(0)$ & $1(50)$ & $0(0)$ & $1(50)$ & \\
\hline
\end{tabular}


Table 6: Bivariate analysis of factors perceived to influence insomnia according to insomnia category among hospitalised patients without a prior history of insomnia at a tertiary care centre in Lebanon $(\mathrm{N}=75)$

\begin{tabular}{|c|c|c|c|c|c|}
\hline \multirow[t]{2}{*}{ Perceived impact } & \multicolumn{4}{|c|}{ Category of insomnia," $\mathbf{n}(\%)$} & \multirow[t]{2}{*}{$P$ value } \\
\hline & $\begin{array}{l}\text { None } \\
(\mathbf{n}=9)\end{array}$ & $\begin{array}{l}\text { Subthreshold } \\
\quad(\mathrm{n}=34)\end{array}$ & $\begin{array}{c}\text { Moderate } \\
(\mathbf{n}=22)\end{array}$ & $\begin{array}{l}\text { Severe } \\
(\mathbf{n}=10)\end{array}$ & \\
\hline Environmental changes & & & & & $0.045^{+}$ \\
\hline None/little & $8(21.1)$ & $19(50)$ & $8(21.1)$ & $3(7.9)$ & \\
\hline Mild/moderate & $1(4.8)$ & $11(52.4)$ & $6(28.6)$ & $3(14.3)$ & \\
\hline Severe/very severe & $0(0)$ & $4(25)$ & $8(50)$ & $4(25)$ & \\
\hline Nurse related factors & & & & & $0.003^{+}$ \\
\hline None/little & $7(17.9)$ & $21(53.8)$ & $9(23.1)$ & $2(5.1)$ & \\
\hline Mild/moderate & $2(13.3)$ & $7(46.7)$ & $6(40)$ & $0(0)$ & \\
\hline Severe/very severe & $0(0)$ & $6(28.6)$ & $7(33.3)$ & $8(38.1)$ & \\
\hline Disease and pain & & & & & 0.120 \\
\hline None/little & 7 (18.4) & $20(52.6)$ & $8(21.1)$ & $3(7.9)$ & \\
\hline Mild/moderate & $2(11.1)$ & $8(44.4)$ & $5(27.8)$ & $3(16.7)$ & \\
\hline Severe/very severe & $0(0)$ & $6(31.6)$ & $9(47.4)$ & $4(21.1)$ & \\
\hline Respiratory symptoms & & & & & 0.159 \\
\hline None/little & $9(14.1)$ & $31(48.4)$ & $17(26.6)$ & $7(10.9)$ & \\
\hline Mild/moderate & $0(0)$ & $0(0)$ & $2(100)$ & $0(0)$ & \\
\hline Severe/very severe & $0(0)$ & $3(33.3)$ & $3(33.3)$ & $3(33.3)$ & \\
\hline Noise and light disturbances & & & & & $0.001^{\dagger}$ \\
\hline None/little & $8(15.4)$ & $30(57.7)$ & $10(19.2)$ & $4 .(7.7)$ & \\
\hline Mild/moderate & $0(0)$ & $0(0)$ & $6(66.7)$ & $3(33.3)$ & \\
\hline Severe/very severe & $1(7.1)$ & 4. (28.6) & $6(42.9)$ & $3(21.4)$ & \\
\hline Stress and anxiety & & & & & $0.003^{\dagger}$ \\
\hline None/little & 7 (14.9) & $26(55.3)$ & $9(19.1)$ & $5(10.6)$ & \\
\hline Mild/moderate & $2(16.7)$ & $6(50)$ & $2(16.7)$ & $2(16.7)$ & \\
\hline Severe/very severe & $0(0)$ & $2(12.5)$ & $11(68.8)$ & $3(18.8)$ & \\
\hline Sharing a room & & & & & 0.161 \\
\hline None/little & $9(16.1)$ & $28(50)$ & $14(25)$ & $5(8.9)$ & \\
\hline Mild/moderate & $0(0)$ & $3(30)$ & 4. (40) & $3(30)$ & \\
\hline Severe/very severe & $0(0)$ & $3(33.3)$ & 4. (44.4) & $2(22.2)$ & \\
\hline
\end{tabular}

*Assessed using an Arabic version of the 7-item Insomnia Severity Index. ${ }^{19,20}$ Scores of 0-7, 8-14, 15-21 and 22-28 were considered indicative of no clinically significant insomnia, subthreshold insomnia, moderate insomnia and severe insomnia, respectively. ${ }^{19}{ }^{\dagger}$ Statistically significant at $P<0.050$.

respiratory symptoms-were not found to interfere significantly with the development of new-onset insomnia. Ho et al. reported similar findings. ${ }^{8}$

In the present study, patients with new-onset insomnia frequently reported the negative impact of various factors on their sleep including environmental changes, nurse-related disturbances (i.e. frequent interruptions to draw blood or check vital signs), disease and pain, noise and brightness, stress and anxiety and sharing a room. Nevertheless, the effect of such disturbances were also reported by patients who did not have insomnia; as such, these factors could not be deemed to significantly affect the development of new-onset insomnia. Ho et al. similarly found that $36 \%$ of hospitalised patients with new-onset insomnia attributed staff disturbances and disease symptoms to be the most common causes of sleep disruption. ${ }^{8}$ 
The current study found a significant decrease in mean ISI score two weeks post-discharge, with the insomnia resolving in $78.7 \%$ of patients initially found to have new-onset insomnia. This result is consistent with Ho et al's study in which $75 \%$ of patients not lost to follow-up reported resolution of their insomnia. ${ }^{8}$ Transient insomnia is defined as insomnia that resolves after removal of the stressor or adaptation of the individual to the nuisance. ${ }^{24}$ Such dramatic rates of resolution therefore support the notion that sudden cases of new-onset in-hospital insomnia are closely tied to factors related to the hospital environment.

Sleep is essential to the process of recovery, with research showing that acute sleep loss in the hospital may be associated with the development of chronic insomnia after discharge, as well as poor longterm health outcomes. ${ }^{10}$ Policymakers and hospital authorities should therefore be vigilant of the need to promote better quality of sleep among inpatients, for instance by optimising hospital rooms and procedures to reduce the frequency and occurrence of sleep disturbances. ${ }^{4}$ Such measures could also potentially improve the recognition and treatment of previously undiagnosed insomnia. ${ }^{10}$ One study indicated that healthcare providers often neglect the evaluation of sleeping hospitalised patients, resulting in frequent sleep disturbances, with the primary reasons for this lack of efficient sleep care being the absence of standardised assessments, poor communication and inadequate comprehension of the importance of sleep to the recovery process. ${ }^{24}$

Certain limitations were encountered in the present study. The inclusion of patients from a single centre in Lebanon could have resulted in selection bias. Residual confounding bias is also possible since the study did not take all factors associated with insomnia into consideration. Moreover, information bias could have occurred since patients often tend to over- or underestimate their symptoms. Nevertheless, the study also had several strengths. Although the sample size was low, it met the necessary number of patients needed for statistical power. Furthermore, an internationally recognised and validated screening tool was used to determine the incidence of insomnia. In addition, this study was the first to exclude patients with a history of insomnia using a validated and translated questionnaire. Finally, an analysis of included and excluded patients showed that they did not appear to differ significantly in terms of sociodemographic characteristics, apart from a higher BMI, thus limiting the likelihood of selection bias.

\section{Conclusion}

The incidence of new-onset hospital-related insomnia among hospitalised patients at a tertiary centre in Lebanon was $88 \%$, with resolution observed two weeks after discharge in $78.7 \%$. The likelihood of new-onset insomnia was significantly greater among patients who shared a room compared to those in single-bed rooms. Patients with new-onset insomnia also had a greater number of night awakenings compared to patients without sleep disturbances, with the number of night awakenings linked to insomnia severity. Further research is recommended to evaluate factors affecting in-hospital sleep disturbances and to develop appropriate solutions to limit insomnia in this population.

\section{CONFLICT OF INTEREST}

The authors declare no conflicts of interest.

\section{FUNDING}

No funding was received for this study.

\section{References}

1. Zaki NF, Yousif M, BaHammam AS, Spence DW, Bharti VK, Subramanian P, et al. Chronotherapeutics: Recognizing the importance of timing factors in the treatment of disease and sleep disorders. Clin Neuropharmacol 2019; 42:80-7. https:// doi.org/10.1097/WNF.0000000000000341.

2. Lipton J, Becker RE, Kothare SV. Insomnia of childhood. Curr Opin Pediatr 2008; 20:641-9. https://doi.org/10.1097/MOP.0b $013 \mathrm{e} 32831897 \mathrm{cb}$.

3. Lichstein $\mathrm{K}$, Taylor $\mathrm{D}$, McCrae $\mathrm{C}$, Ruiter ME. Insomnia: Epidemiology and risk factors. In: Kryger MH, Roth T, Dement WC (Eds). Principles and Practice of Sleep Medicine, 5th ed. Philadelphia, Pennsylvania: Saunders, 2010. pp. 827-37.

4. Mai E, Buysse DJ. Insomnia: Prevalence, impact, pathogenesis, differential diagnosis, and evaluation. Sleep Med Clin 2008; 3:167-74. https://doi.org/10.1016/j.jsmc.2008.02.001.

5. Colten HR, Altevogt BM. Improving awareness, diagnosis, and treatment of sleep disorders. In: Sleep Disorders and Sleep Deprivation: An unmet public health problem. Washington D.C., USA: National Academies Press, 2006.

6. Reynolds CF 3rd, Redline S. The DSM-V sleep-wake disorders nosology: An update and an invitation to the sleep community. J Clin Sleep Med 2010; 6:9-10. https://doi.org/10.5664/jcsm.27703.

7. Reynolds CF 3rd, O'Hara R. DSM-5 sleep-wake disorders classification: Overview for use in clinical practice. Am J Psychiatry 2013; 170:1099-101. https://doi.org/10.1176/appi.ajp.20 13.13010058 .

8. Ho A, Raja B, Waldhorn R, Baez V, Mohammed I. New onset of insomnia in hospitalized patients in general medical wards: Incidence, causes, and resolution rate. J Community Hosp Intern Med Perspect 2017; 7:309-13. https://doi.org/10.1080/ 20009666.2017.1374108.

9. Talih F, Ajaltouni J, Ghandour H, Abu-Mohammad AS, Kobeissy F. Insomnia in hospitalized psychiatric patients: Prevalence and associated factors. Neuropsychiatr Dis Treat 2018; 14:969-75. https://doi.org/10.2147/NDT.S160742. 
10. Stewart NH, Arora VM. Sleep in hospitalized older adults. Sleep Med Clin 2018; 13:127-35. https://doi.org/10.1016/j. jsmc.2017.09.012.

11. Smith MT, Klick B, Kozachik S, Edwards RE, Holavanahalli R, Wiechman S, et al. Sleep onset insomnia symptoms during hospitalization for major burn injury predict chronic pain. Pain 2008; 138:497-506. https://doi.org/10.1016/j.pain.2008.01.028.

12. Knutson KL, Van Cauter E. Associations between sleep loss and increased risk of obesity and diabetes. Ann N Y Acad Sci 2008; 1129:287-304. https://doi.org/10.1196/annals.1417.033.

13. Gambhir IS, Chakrabarti SS, Sharma AR, Saran DP. Insomnia in the elderly: A hospital-based study from North India. J Clin Gerontol Geriatr 2014; 5:117-21. https://doi.org/10.1016/j. jcgg.2014.05.005

14. Ellis JG, Gehrman P, Espie CA, Riemann D, Perlis ML. Acute insomnia: Current conceptualizations and future directions. Sleep Med Rev 2012; 16:5-14. https://doi.org/10.1016/j.smrv.20 11.02.002.

15. Macfarlane M, Rajapakse S, Loughran S. What prevents patients sleeping on an acute medical ward? An actigraphy and qualitative sleep study. Sleep Health 2019; 5:666-9. https://doi. org/10.1016/j.sleh.2019.06.012.

16. Axén I. Pain-related sleep disturbance: A prospective study with repeated measures. Clin J Pain 2016; 32:254-9. https:// doi.org/10.1097/AJP.0000000000000249.

17. Dijk DJ, Archer SN. Light, sleep, and circadian rhythms: Together again. PLoS Biol 2009; 7:e1000145. https://doi. org/10.1371/journal.pbio.1000145.
18. Lawrence JW, Fauerbach J, Eudell E, Ware L, Munster A. The 1998 Clinical Research Award: Sleep disturbance after burn injury - A frequent yet understudied complication. J Burn Care Rehabil 1998; 19:480-6. https://doi.org/10.1097/00004630199811000-00005.

19. Bastien $\mathrm{CH}$, Vallières $\mathrm{A}$, Morin $\mathrm{CM}$. Validation of the Insomnia Severity Index as an outcome measure for insomnia research. Sleep Med 2001; 2:297-307. https://doi.org/10.1016/s13899457(00)00065-4

20. Hallit S, Haddad C, Hallit R, Al Karaki G, Malaeb D, Sacre H, et al. Validation of selected sleeping disorders related scales in Arabic among the Lebanese population. Sleep Biol Rhythms 2019; 17:183-9. https://doi.org/10.1007/s41105-018-0196-0.

21. Buysse DJ, Reynolds CF 3rd, Monk TH, Berman SR, Kupfer DJ. The Pittsburgh Sleep Quality Index: A new instrument for psychiatric practice and research. Psychiatry Res 1989; 28:193-213. https://doi.org/10.1016/0165-1781(89)90047-4.

22. Suleiman KH, Yates BC, Berger AM, Pozehl B, Meza J. Translating the Pittsburgh Sleep Quality Index into Arabic. West J Nurs Res 2010; 32:250-68. https://doi.org/10.1177/0193945909348230.

23. Suleiman $\mathrm{KH}$, Yates BC. Translating the Insomnia Severity Index into Arabic. J Nurs Scholarsh 2011; 43:49-53. https://doi. org/10.1111/j.1547-5069.2010.01374.x.

24. Chokroverty MS, Sahota MP (Eds). Acute and Emergent Events in Sleep Disorders. Oxford, UK: Oxford University Press, 2011. https://doi.org/10.1093/med/9780195377835.001.0001. 